\title{
Soil structure and bypass flow processes in a Vertisol under sprinkler and drip irrigation
}

\author{
G. Crescimanno* , A. De Santis, G. Provenzano \\ Università di Palermo, Dipartimento ITAF, Sezione Idraulica, Viale delle Scienze 12, 90128 Palermo, Italy
}

Received 18 July 2005; received in revised form 14 September 2006; accepted 31 October 2006

Available online 14 December 2006

\begin{abstract}
In this paper morphological and physical characteristics, as well as flow behaviour of a Mediterranean Vertisol under the influence of two different irrigation systems currently used for irrigation, i.e. drip and sprinkler systems, were compared. No differences in soil texture, compaction and in potential cracking were found on cores from the two fields. However, field application of methylene blue showed the presence of continuous macropores, penetrating up to depths of $20-25 \mathrm{~cm}$ from the soil surface, in the field where the drip system was in use (field 1). This was considered to be the pre-existing soil structure. Instead, macropores terminating at a depth ranging between 5 and $10 \mathrm{~cm}$ from the soil surface were observed in the sprinkler irrigated field (field 2). The same difference in terms of macropores' continuity was also observed on soil cores sampled from the two irrigated fields. The higher raindrop impact and the non-point water application involved in the sprinkler irrigation system were assumed to have determined, during several years, the different depth of penetration of the macropores in the two fields. A different hydraulic behaviour was evidenced by laboratory measurement of bypass flow on soil cores taken from the two fields. Specifically, higher values of the saturated hydraulic conductivity were found in the cores from the drip irrigated field compared to those sampled in the sprinkler field. In addition no bypass flow was measured in the columns under the sprinkler field, while high rates and amounts of bypass flow were obtained in the cores taken from the drip irrigated field. The different hydraulic behaviour observed in the cores taken from the drip and from the sprinkler irrigated field was in agreement with the difference in terms of macropores' continuity between the two fields. Being bypass flow a mechanism inducing leaching of solutes, results of this investigation suggest that irrigation systems affecting soil structure, and altering macropores' continuity, should be avoided in clay soils.
\end{abstract}

(C) 2006 Published by Elsevier B.V.

Keywords: Bypass flow; Soil structure; Drip irrigation; Sprinkler irrigation

\section{Introduction}

The agricultural production and the development of arid and semi-arid regions rely mainly on irrigation. However, without appropriate management, irrigated agriculture can be detrimental to the environment and endanger sustainability. Therefore, the goal of modern irrigation is to develop methods allowing to save water and to improve both the water and the salt distribution within the root zone, also preserving maintenance of good structural conditions.

Soil structure is important in many soil processes, especially in fine-textured soils. Adverse changes to the structure and

\footnotetext{
* Corresponding author. Tel.: +39 091 7028109; fax: +39 091484035 .

E-mail address: gcrescim@unipa.it (G. Crescimanno).
}

physical properties of soils under agriculture have been termed soil structural degradation (Williams and Chartres, 1991).

Nielsen et al. (1986) defined structured soils as "soils that contain relatively large or more or less continuous voids, such as inter-aggregate pores, inter-pedal voids, earthworms and gopher holes, drying cracks in clay soils, decayed root channels and other types of macro-pores". Kay (1990) defined structural form as the heterogeneous arrangement of solid and void space that exists in a soil at a given time. Structural form can be described through total porosity, pore-size distribution and continuity of the pore system. Pore continuity is very important for many soil functions. Continuity of macropores and/or cracks in structured soils has been documented to determine rates of movement of solutes or contaminants much faster than those that could be explained by considering basic transport and 
adsorption parameters of the soil material. Flow of water under these conditions has been termed preferential flow or bypass flow (Bouma, 1984) and defined as "the flow of water through a system of large pores that allows fast flow velocities and bypasses the unsaturated zone" (Beven and Germann, 1982).

The mobility of chemicals in soils is affected by continuity as well as by the size of the macropores and/or cracks (Steenhuis and Parlange, 1991). Instead, total macroporosity is not a very relevant property in relation to water flow processes such as bypass flow as very few macropores, contributing little to total macroporosity, may dominate transport of water and solutes (Bouma and Dekker, 1978).

Many techniques are available to quantify macroporosity, such as scanning methods (Heijs et al., 1996), breakthrough curves (Kung et al., 2000) and dye staining techniques (Bouma and Dekker, 1978). The latter technique, combined with digital image processing methods, has many advantages (Droogers et al., 1998). Measurement can be easily performed directly in the field. Moreover, the observed macropores from staining technique do not include all the macropores but identify only those pores connected to the infiltration surface, i.e. the continuous pores, which are relevant to bypass flow (Booltink and Bouma, 1991).

Management practices have a considerable effect on soil structure and consequently on the overall sustainability of the agricultural production system (Bouma, 1991). Irrigation methods may affect the water and salt regime in the root zone and their uniform distribution within the irrigated field, with significant effects on crop yield (Warrick and Gardner, 1983). A common irrigation method, world-wide used, is the sprinkler. Moving sprinkler irrigation systems and center-pivot systems are widely used in the US and other countries, such as in Israel (Ben-Hur, 1994). Features of sprinkler system making it popular are automation, large areas coverage and ability to operate on relatively rough terrain. However, this system is sometimes characterized by a relatively high instantaneous rate of water application (Gilley and Mielke, 1980).

Many studies have investigated and documented the effect of raindrop impact on surface soil structure such as aggregate stability, sealing and crusting (Gilley and Mielke, 1980; BenHur, 1994) in loess soils (Ben-Hur et al., 1989, 1995; Huang et al., 2000), which are sensitive to seal formation (Agassi et al., 1981). However, Vertisols commonly occur in arid and semiarid regions (Yaalon and Kalmar, 1978) and behave differently during irrigation with sprinkler systems compared to loess soils. A Vertisol is defined as a deep soil ( $>0.5 \mathrm{~m}$ depth) containing $30 \%$ or more clay in all horizons, with Montmorillonite as dominant clay (FAO, 1990). The high clay content in a Vertisol may increase aggregate stability (Kemper and Koch, 1966), diminishing seal formation, and affecting the hydraulic properties of soil body (Ben-Hur and Assouline, 2002). In Vertisols, plugging of pores with detached particles transported by water (Rands et al., 1986) could thus be hypothesized to be the main consequence of sprinkler irrigation. However, only in a few papers the effect of raindrop impact under sprinkler irrigation on hydraulic properties of Vertisols has been investigated (Ben-Hur et al., 1998). No studies appear to have investigated if changes in structural form, and especially in pores continuity, caused by redistribution of soil particles and plugging of soil pores under sprinkler irrigation, may have consequences on flow behaviour occurring in Vertisols.

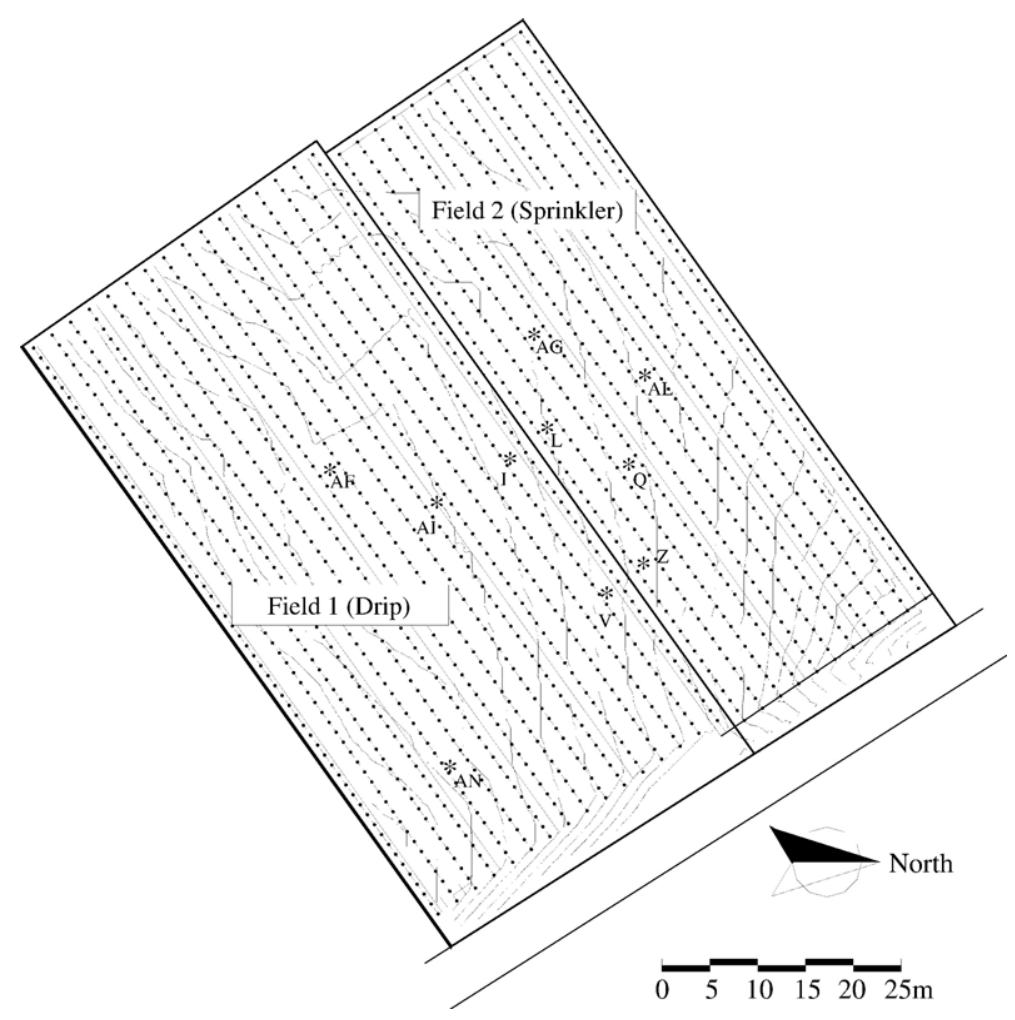

Fig. 1. Map of the two fields with the locations of the sampling sites. 
Table 1

Classification and physical characteristics of the soil

\begin{tabular}{|c|c|c|c|c|c|c|c|c|c|}
\hline \multirow{3}{*}{$\frac{\text { Horizon } 1}{\text { Classification } \uparrow}$} & \multicolumn{4}{|c|}{$A p(0-15 \mathrm{~cm})$} & \multicolumn{5}{|c|}{$\mathrm{C} 1(15-40 \mathrm{~cm})$} \\
\hline & \multicolumn{9}{|c|}{ Vertic chromoxerert } \\
\hline & $\begin{array}{l}\text { Soil } \\
\text { site }\end{array}$ & $\begin{array}{l}\mathrm{Sa} \\
{[\%]}\end{array}$ & $\begin{array}{l}\mathrm{Si} \\
{[\%]}\end{array}$ & $\begin{array}{l}\mathrm{C} \\
{[\%]}\end{array}$ & $\begin{array}{l}\mathrm{Sa} \\
{[\%]}\end{array}$ & $\begin{array}{l}\mathrm{Si} \\
{[\%]}\end{array}$ & $\begin{array}{l}\mathrm{C} \\
{[\%]}\end{array}$ & $\begin{array}{l}K_{\text {(sat) }} \\
{[\mathrm{cm} / \mathrm{h}]}\end{array}$ & $\begin{array}{l}D_{(\max )} \\
{[\mathrm{cm}]}\end{array}$ \\
\hline \multirow{7}{*}{$\begin{array}{l}\text { Field } 1 \\
\qquad \text { (drip } \\
\text { irrigation) }\end{array}$} & $\mathrm{V}$ & 36 & 32 & 32 & 28 & 37 & 35 & 3.70 & 25 \\
\hline & I & 35 & 33 & 32 & 32 & 34 & 34 & 3.78 & 20 \\
\hline & AN & 36 & 33 & 31 & 35 & 33 & 32 & 2.58 & 20 \\
\hline & $\mathrm{AF}$ & 34 & 33 & 33 & 38 & 32 & 30 & 2.69 & 22 \\
\hline & AI & 41 & 30 & 29 & 35 & 34 & 32 & 1.34 & 20 \\
\hline & Mean & 36.4 & 32.2 & 31.4 & 33.5 & 34.0 & 32.5 & & \\
\hline & S.D. & 3.0 & 1.4 & 1.6 & 3.5 & 1.7 & 2.0 & & \\
\hline \multirow{7}{*}{$\begin{array}{l}\text { Field } 2 \text { (sprinkler } \\
\quad \text { irrigation) }\end{array}$} & Z & 38 & 32 & 31 & 27 & 37 & 36 & 0.26 & 5 \\
\hline & $\mathrm{L}$ & 35 & 33 & 33 & 31 & 34 & 35 & 2.01 & 10 \\
\hline & Q & 39 & 31 & 30 & 33 & 34 & 33 & 0.43 & 10 \\
\hline & $\mathrm{AG}$ & 39 & 32 & 29 & 36 & 32 & 33 & 1.18 & 10 \\
\hline & $\mathrm{AL}$ & 36 & 33 & 31 & 31 & 34 & 35 & 0.91 & 6 \\
\hline & Mean & 37.3 & 31.9 & 30.7 & 31.7 & 34.2 & 34.1 & & \\
\hline & S.D. & 1.9 & 0.8 & 1.3 & 3.2 & 2.0 & 1.4 & & \\
\hline
\end{tabular}

$\dagger$ Soil taxonomy (Soil Survey Staff, 1992).

$\mathrm{Sa}=$ Sand $(2-0.02 \mathrm{~mm})$.

$\mathrm{Si}=$ Silt $(0.02-0.002 \mathrm{~mm})$.

$\mathrm{C}=$ Clay $(<0.002 \mathrm{~mm})$.

$K_{\text {(sat) }}=$ saturated hydraulic conductivity.

$D_{\max }=$ maximum macropores depth measured in the field.

Investigations were performed from 1999 to 2001 in a study area located in Sicily (Mazara del Vallo, Trapani) in the frame of a European project aimed at developing management practices preventing land degradation under irrigation with saline water. Sprinkler and drip systems are generally used to irrigate crops in the area. Two neighbouring fields characterized by the same Vertisol (Typic Chromoxerert) but under sprinkler and drip irrigation were considered. The two irrigation systems were hypothesized to have a different impact on soil structural properties, potentially affecting the soil hydraulic properties as well as flow behaviour under rainfall and/or irrigation.

Thus, the specific objectives of this study were to investigate (i) if differences in the structural form, and specifically in the continuity of macropores and/or cracks, occurred in the soil under the two irrigation systems and (ii) if these changes in structural form affected flow behaviour under simulated rainfall.

\section{Materials and methods}

\subsection{Study-area and sampling sites}

Two neighbouring fields were selected in a Sicilian irrigated catchment, located in the area of Mazara del Vallo $\left(37^{\circ} 40^{\prime} \mathrm{N}\right.$, $\left.12^{\circ} 40^{\prime} \mathrm{E}\right)$. The two fields are irrigated with the same water (Sodium Adsorption Ratio, $\mathrm{SAR}=5(\mathrm{~mol} / \mathrm{l})^{0,5}$; Electrical Conductivity, $\mathrm{EC}=2 \mathrm{dS} / \mathrm{m})$ under two irrigation systems, i.e. drip irrigation (field 1, dimension: $30 \times 85 \mathrm{~m}$ ) and sprinkler irrigation (field 2, dimension: $40 \times 85 \mathrm{~m}$ ). The drip and the sprinkler systems supply a specific flow rate of $22 \mathrm{~m}^{3} / \mathrm{h} / \mathrm{Ha}$ and $104 \mathrm{~m}^{3} / \mathrm{h} / \mathrm{Ha}$, respectively.

Fig. 1 illustrates the topography of the area and the sampling sites. Five locations were randomly selected in each field as illustrated in Fig. 1. In each location a ring with diameter of $25 \mathrm{~cm}$ was inserted and a $0.01 \mathrm{M}$ methylene blue solution was ponded into the ring on top of the soil surface, to determine an infiltration rate (IR) exceeding the saturated hydraulic conductivity $\left(K_{(s a t)}\right)$ of the soil matrix, and a drainage process accounting by macropores (Bouma and Dekker, 1978). After one day the soil was removed in layers of 5, 10, 15, 20 and $25 \mathrm{~cm}$ from the surface, in order to visualize the maximum depth of penetration of macropores, and pictures were taken at each layer.

\subsection{Soil shrinkage and hydraulic characteristics}

Undisturbed soil cores ( $8.5 \mathrm{~cm}$ diameter by $11.5 \mathrm{~cm}$ long) were sampled from the $\mathrm{C} 1$ horizon of each field, nearby the sites where methylene blue was previously applied, in order to determine the soil shrinkage characteristic curve (SSCC), which was determined by measuring vertical and horizontal shrinkage (Crescimanno and Provenzano, 1999).

The coefficient of linear extensibility, COLE, was calculated according to Grossman et al. (1968):

COLE $=\left(\frac{V_{\text {wet }}}{V_{\text {dry }}}\right)^{\frac{1}{3}}-1$

with $V_{\text {wet }}$ volume at saturation and $V_{\text {dry }}$ volume at the air-dry condition.

Five undisturbed soil cores (20-cm diameter by $20-\mathrm{cm}$ height) were also sampled from the same locations into fields 1 and 2. The hydraulic conductivity of the soil matrix at

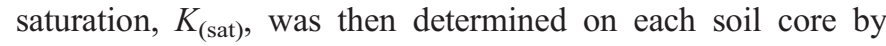
the suction crust infiltrometer method (SCIM) (Booltink et al., 1991).

\subsection{Bypass flow measurements}

After measuring $K_{\text {(sat) }}$, each core was placed on a funnel connected to an outflow collector equipped with a pressure transducer and two tensiometers were installed at $-4 \mathrm{~cm}$ and $-8 \mathrm{~cm}$ from the soil surface. These tensiometers provided information on: (i) the initial pressure head in the soil; (ii) the time when water started to infiltrate in the macropores (top

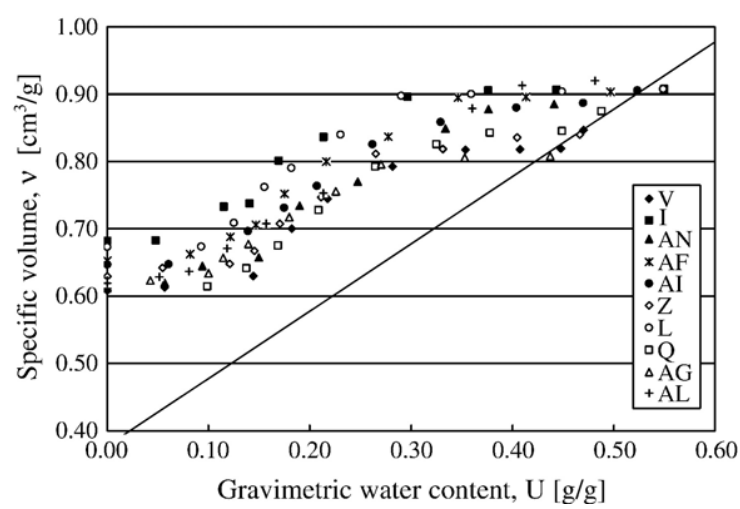

Fig. 2. Specific volume $v$ as a function of gravimetric water content $U$ obtained for samples collected in fields 1 (black dots) and 2 (white dots). 
tensiometer) and (iii) the hydraulic conditions in the upper part of the soil column.

Using a rain simulator, rain showers with intensities $\left(I_{\mathrm{r}}\right)$ higher than the measured $K_{\text {(sat) }}$ were applied on top of the samples in order to induce bypass flow (Booltink et al., 1993; Crescimanno et al., 2002).

\subsection{Laboratory application of methylene blue and analysis of stained patterns}

After bypass flow measurements the cores were dried to the initial conditions prior to the experiments, and a $0.01 \mathrm{M}$ methylene blue solution was poured on the top. The cores were left air-drying for one day, then peeled-off in layers of $2 \mathrm{~cm}$ from the top, and a photograph was taken at each layer. Stained patterns of methylene

a)

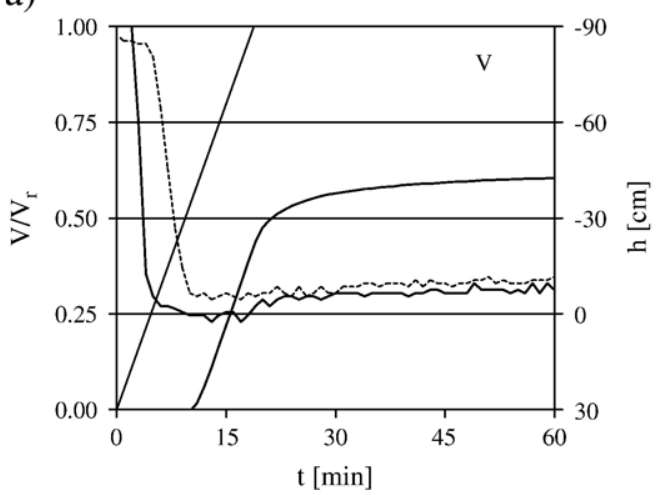

c)

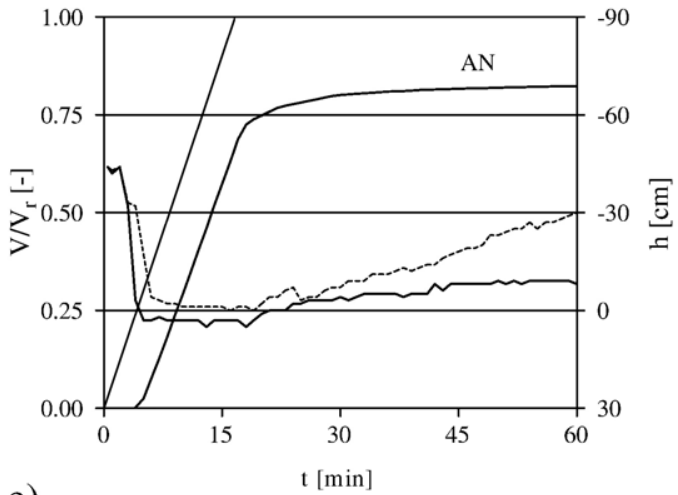

e)

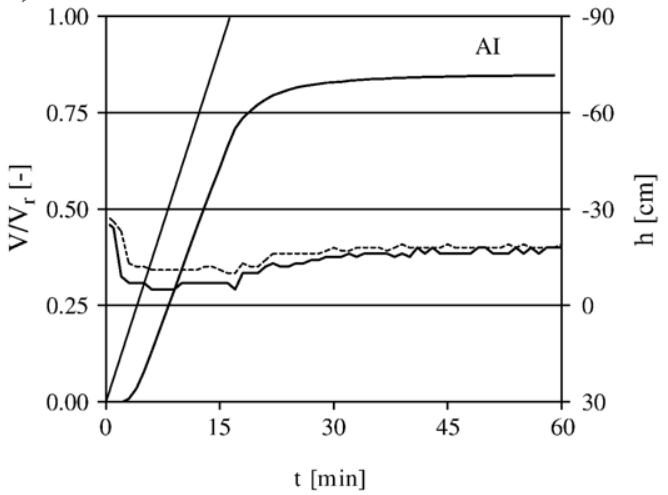

blue at the different depths were recognized by an image analysis carried out by means of the Erdas Imagine software (ERDAS Inc., Atlanta, USA). Colour photographs were scanned and corrected for geometric distortion, illumination inhomogeneities and colour differences between photographs. The images were then analyzed and each pixel was classified as stained or unstained on the basis of the observed intensity of its blue, green and red colours. Each picture was constituted by a number of about 400,000 pixels, with a pixel representing approximately an area of $0.08 \mathrm{~mm}^{2}$. This procedure made it possible to calculate macropores' areas at each depth.

Significance of the differences between the mean values of the macropores areas, determined on the soil cores from the two fields, was tested by analysis of variance (ANOVA). All tests were performed at a 0.05 significance level.

b)

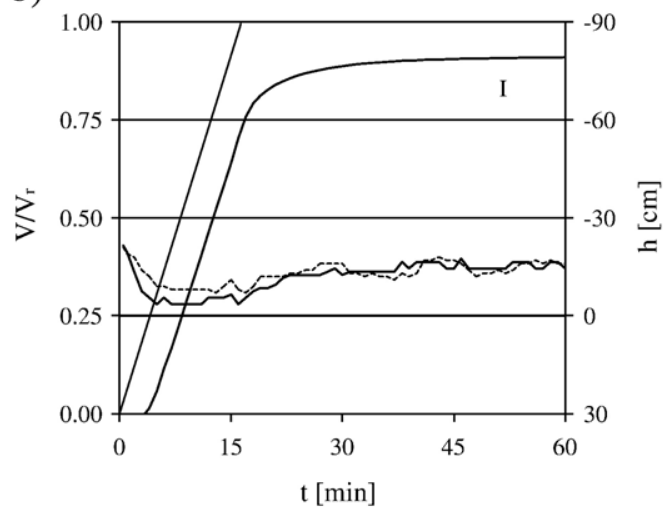

d)

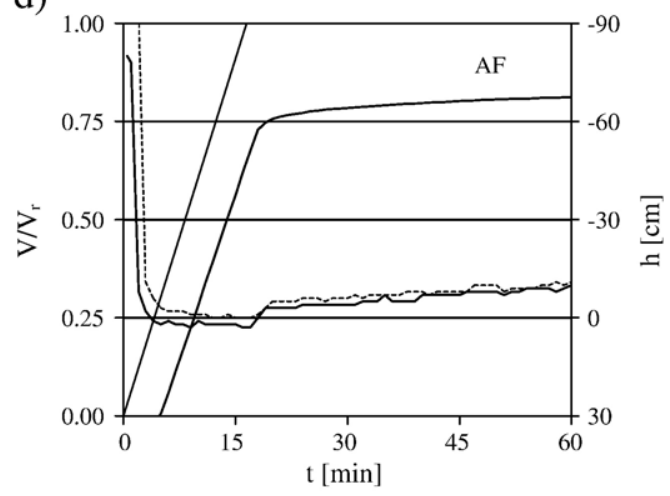

Fig. 3. (a-e) Cumulative relative inflow (light solid line) and outflow (marked solid line) volumes and matric potential (solid and dashed lines refer to the top and bottom tensiometers respectively) as a function of time (cores from field 1). 


\section{Results and discussion}

\subsection{Soil physical and hydraulic properties}

Table 1 reports classification (Soil Survey Staff, 1992) and the soil textural composition at the selected locations in the two fields. Analysis of variance showed that the mean values of clay (C), sand (SA) and silt (Si) measured in field 1 were not significantly different from those measured in field 2. Analysis of the soil shrinkage characteristic curves obtained on the cores from fields 1 and 2 (Fig. 2), expressed as specific volume (v) vs. gravimetric water content $(U)$, showed no significant differences in the mean $v$ values, at fixed $U$. This means that the same porosity, as well as the same degree of compaction, existed between the cores from the two fields. The mean values of COLE determined on the basis of the SSCCs measured on the cores taken from field 1 was 0.082 , and the mean values of COLE determined on the cores taken from field 2 was 0.084 . No significant differences were therefore found between the two mean COLE values $(P=0.05)$. According to Parker et al. (1977), the cores from the two fields were both classified as having a high rate of shrink-swell potential. No difference was found between the cores from the two fields in terms of potential cracking. However, continuous macropores penetrating till a depth $\left(D_{\max }\right)$ from 20 to $25 \mathrm{~cm}$ (mean value $21.4 \mathrm{~cm}$ ) (Table 1), were evidenced in field 1 by visual analysis of the methylene blue patterns. On the contrary, macropores terminating from 5 to $10 \mathrm{~cm}$ (mean value $8.2 \mathrm{~cm}$ ), were found in field 2.

The hydraulic conductivity at saturation, $K_{\text {(sat) }}$, measured by the SCIM (Table 1), showed that lower $K_{\text {(sat) }}$ were obtained on the cores from field 2 than on cores from field 1. Since nonsignificantly different porosity, compaction, and potential cracking were found between the cores from the two fields, the higher $K_{\text {(sat) }}$ values measured in the cores from field 1 reflected the continuous macropores observed in this field (Bouma, 1991). On the contrary, the shorter macropores observed in field 2 explained the lower $K_{\text {(sat) }}$ values measured in the sprinkler irrigated field.

\subsection{Bypass flow measurements}

Fig. 3a-e shows the results of bypass flow experiments performed on the V, I, AN, AF and AI cores of field 1, under a constant rate of water application. The figures report the outflow volume, $V$, divided by the volume of the applied water, $V_{\mathrm{r}}$, as a function of time, together with the matric potential $(\mathrm{h})$ recorded by the two tensiometers. The cumulative outflow curves all showed identical behaviour. After the time when outflow starts, $t_{\mathrm{d}}$, an exponential progression (ESO) between the times $t_{\mathrm{d}}$ and $t_{\mathrm{cs}}$ (start of linear outflow) could be observed. Between $t_{\mathrm{cs}}$ and $t_{\mathrm{e}}$ (end of linear outflow) there was a nearly linear outflow pattern, and after $t_{\mathrm{e}}$ an exponential fade out pattern was evident. The linear outflow occurring between $t_{\mathrm{cs}}$ and $t_{\mathrm{e}}$ (i.e. the time derivative of outflow is constant) was observed in earlier measurements (van Stiphout et al., 1987; Booltink et al., 1993; Crescimanno et al., 2002).

Table 2 reports some relevant parameters deduced from the inflow/outflow curves. As can be seen in the table, for the cores from field 1 the outflow process started during the rainfall application $\left(t_{\mathrm{d}}<t_{\mathrm{r}}\right)$, and occurred when the bottom tensiometer records a negative matric potential (h). The outflow volume $V$ $\left(t_{\mathrm{e}}\right)$, which represented the bypass flow, was a relevant percentage of the applied rainfall volume $\left(1000 \mathrm{~cm}^{3}\right)$, ranging from $40.9 \%$ to $70.9 \%$. The outflow rate during steady-state, $O_{\mathrm{r}}$, reported in Table 2, was almost equal to the application rate, $I_{\mathrm{r}}$, indicating the very low adsorption of water on the macropores/ cracks walls during the bypass flow process, and confirming the occurrence of bypass flow (Booltink et al., 1993; Crescimanno et al., 2002).

Table 2

Parameters of the outflow curves obtained by the bypass flow measurement

\begin{tabular}{|c|c|c|c|c|c|c|c|c|c|c|}
\hline & Soil cores & $h_{\mathrm{I}}[\mathrm{cm}]$ & $I_{\mathrm{r}}[\mathrm{cm} / \mathrm{h}]$ & $t_{\mathrm{r}}[\mathrm{min}]$ & $t_{\mathrm{d}}[\mathrm{min}]$ & $t_{\mathrm{cs}}[\mathrm{min}]$ & $t_{\mathrm{e}}[\mathrm{min}]$ & $V\left(t_{\mathrm{e}}\right) / V_{\mathrm{r}}[\%]$ & $O_{\mathrm{r}}[\mathrm{cm} / \mathrm{h}]$ & $D_{(\max )}^{\prime}[\mathrm{cm}]$ \\
\hline \multirow[t]{5}{*}{ Field 1 (drip irrigation) } & $\mathrm{V}$ & -90.4 & 10.2 & 18.8 & 10.3 & 11.9 & 18.5 & 40.9 & 10.2 & 16 \\
\hline & $\mathrm{I}$ & -21.0 & 11.7 & 16.4 & 3.4 & 6.3 & 15.0 & 64.5 & 11.3 & 16 \\
\hline & $\mathrm{AN}$ & -44.0 & 11.5 & 16.7 & 3.8 & 6.1 & 16.7 & 68.8 & 10.5 & 16 \\
\hline & $\mathrm{AF}$ & -93.0 & 11.6 & 16.5 & 4.8 & 4.9 & 16.4 & 64.2 & 10.6 & 16 \\
\hline & AI & -26.0 & 11.7 & 16.4 & 2.3 & 6.0 & 17.0 & 70.9 & 10.1 & 16 \\
\hline \multirow[t]{5}{*}{ Field 2 (sprinkler irrigation) } & $\mathrm{Z}$ & -68.4 & 11.2 & 17.0 & 24.0 & & & & 1.2 & 16 \\
\hline & $\mathrm{L}$ & -49.0 & 11.5 & 16.7 & 6.9 & 6.4 & 23.5 & 63.5 & 7.3 & 16 \\
\hline & Q & -90.0 & 11.0 & 17.4 & 12.3 & & & & 1.2 & 16 \\
\hline & $\mathrm{AG}$ & -82.0 & 11.8 & 16.2 & 18.8 & & & & 1.7 & 16 \\
\hline & $\mathrm{AL}$ & -26.0 & 10.8 & 17.6 & 7.8 & & & & 1.2 & 16 \\
\hline
\end{tabular}

$h_{\mathrm{i}}=$ initial matric potential.

$t_{\mathrm{r}}=$ rainfall duration.

$t_{\mathrm{d}}=$ time-start of outfow.

$t_{\mathrm{cs}}=$ time-start of linear outflow.

$t_{\mathrm{e}}=$ time-stop of linear outflow.

$V\left(t_{\mathrm{e}}\right)=$ cumulative outflow at the time $t_{\mathrm{e}}$.

$V_{\mathrm{r}}=$ rainfall volume.

$I_{\mathrm{r}}=$ rainfall intensity

$O_{\mathrm{r}}=$ outflow rate.

$D_{(\max )}^{\prime}=$ maximum macropores depth measured in the cores. 
a)

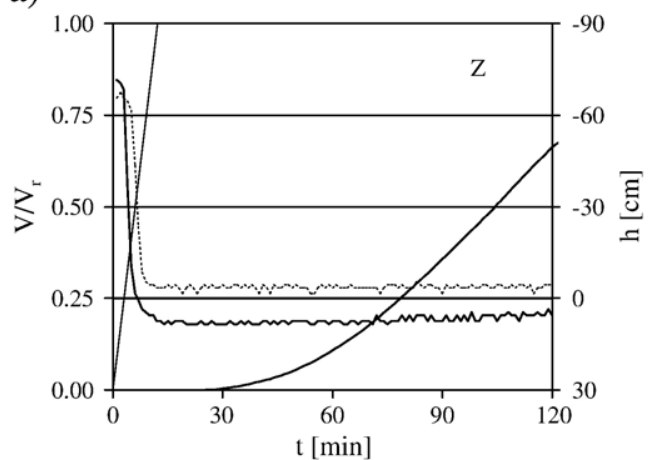

c)

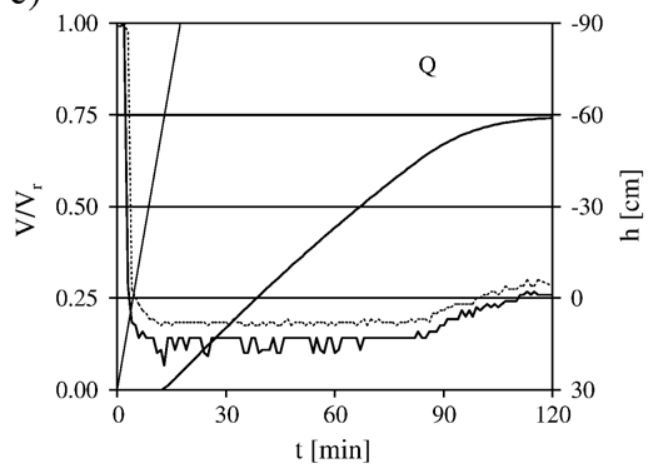

e)

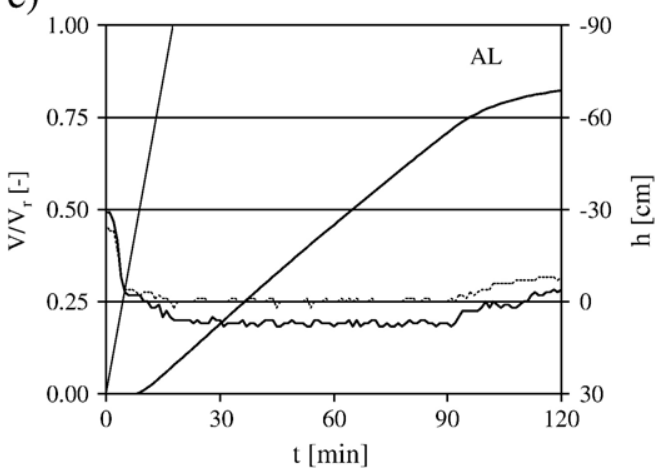

b)

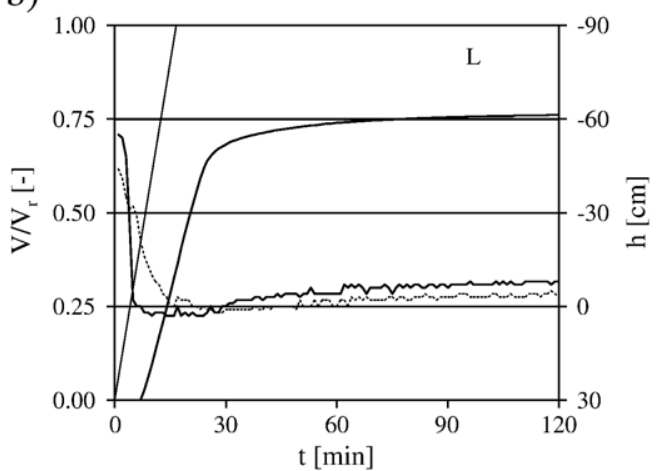

d)

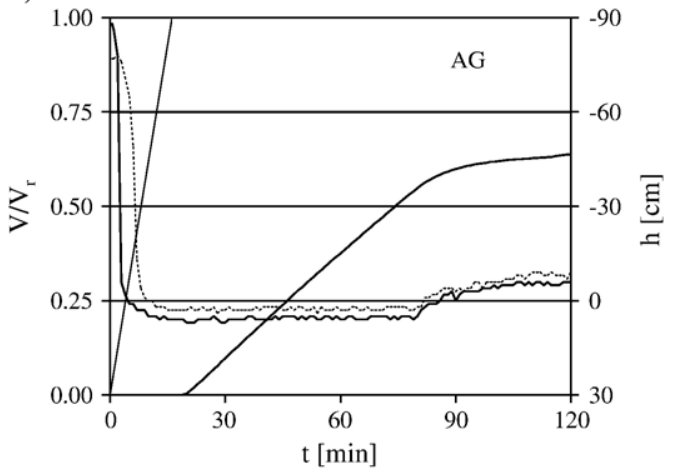

Fig. 4. (a-e) Cumulative relative inflow (light solid line) and outflow (marked solid line) volumes and matric potential (solid and dashed lines refer to the top and bottom tensiometers respectively) as a function of time (cores from field 2).

Fig. $4 \mathrm{a}-\mathrm{e}$ shows the results of the bypass flow experiments performed on the Z, L, Q, AG and AL cores of field 2. Analysis of Table 2 for the cores taken from field 2 evidenced that for the
$\mathrm{Z}, \mathrm{Q}, \mathrm{AG}$ and $\mathrm{AL}$ cores the outflow process started when the bottom tensiometer indicated conditions of saturation or ponding $(h \geq 0)$, and that $O_{\mathrm{r}}$ was much lower than $I_{\mathrm{r}}$. These

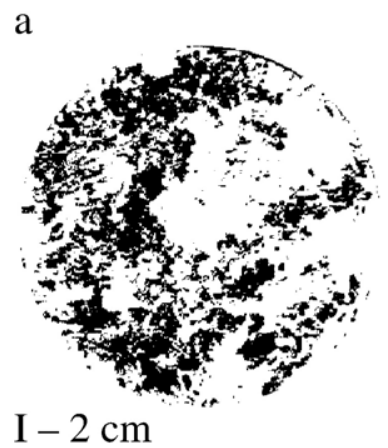

b

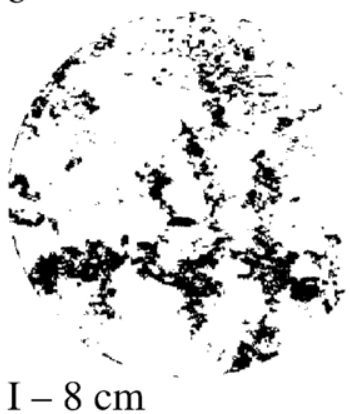

$\mathrm{c}$

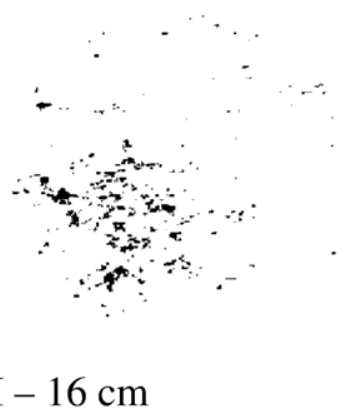

Fig. 5. $(\mathrm{a}-\mathrm{c})$ Methylene blue patterns in the I sample, obtained at three different depths. 
a

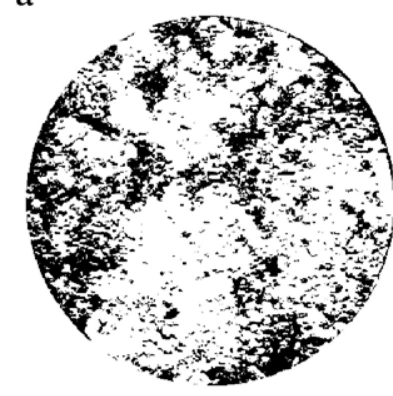

$\mathrm{Z}-2 \mathrm{~cm}$ $\mathrm{b}$

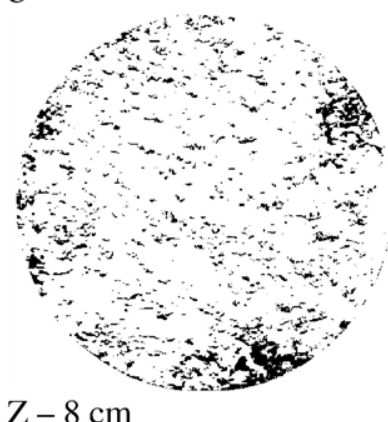

$\mathrm{C}$

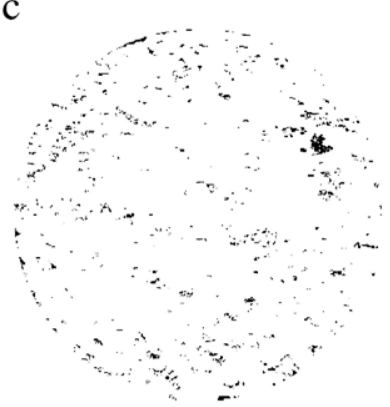

$\mathrm{Z}-10 \mathrm{~cm}$

Fig. 6. $(\mathrm{a}-\mathrm{c})$ Methylene blue patterns in the $\mathrm{Z}$ sample, obtained at three different depths.

conditions demonstrated the absence of bypass flow, and the occurrence of Darcian flow. This flow behaviour was in agreement with the morphological patterns generally observed in the sprinkler irrigated field, which showed less penetrating macropores into field 2, and confirmed the role of continuous macropores on the rate and amount of bypass flow (Bouma,
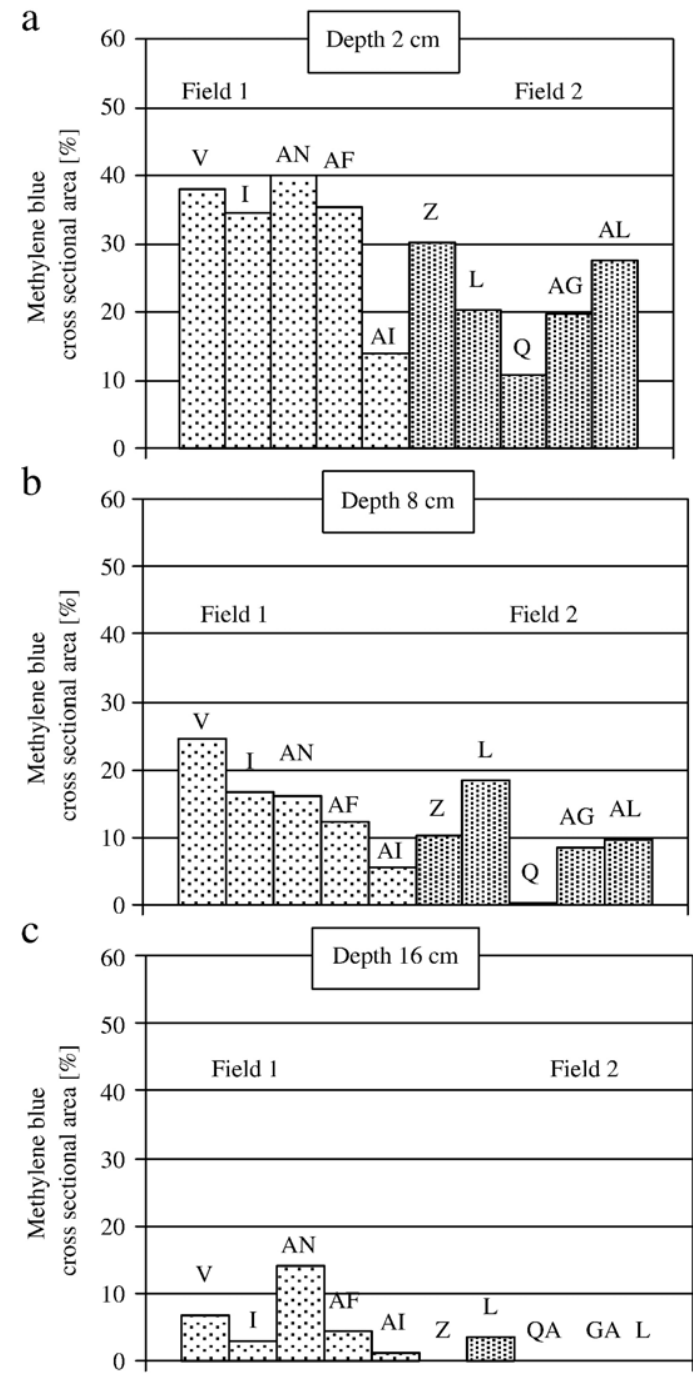

Fig. 7. (a-c) Percentage of the methylene blue cross sectional area at the depths of $2 \mathrm{~cm}, 8 \mathrm{~cm}$ and $16 \mathrm{~cm}$, for all the soil samples.
1991). Only for the L sample the outflow curves showed a behaviour intermediate between that observed in the cores from field 1 and those from field 2. The outflow process started during the rainfall application $\left(t_{\mathrm{d}}<t_{\mathrm{r}}\right)$ when the bottom tensiometer indicated unsaturated conditions $(h<0)$. The outflow rate during steady-state, $O_{\mathrm{r}}$, was lower than those observed in the cores from field 1 but higher than the $O_{\mathrm{r}}$ rates generally found in the cores of field 2 .

As discussed in the following paragraph, this behaviour, indicating a certain occurrence and amount of bypass flow, was the consequence of the greater depth of penetration of macropores in the L core compared to that found in the other samples taken from field 2 .

\subsection{Analysis of the methylene blue stained areas}

Figs. $5 \mathrm{a}-\mathrm{c}$ and $6 \mathrm{a}-\mathrm{c}$ illustrate the methylene blue patterns obtained for the cores I (field 1) and Z (field 2) respectively, at three different depths. The figures show that the methylene blue areas (black areas) tended to decrease at increasing depth.

Fig. $7 \mathrm{a}-\mathrm{c}$ shows the methylene blue area expressed as percentage of the sample area, at the depths of $2 \mathrm{~cm}, 8 \mathrm{~cm}$ and $16 \mathrm{~cm}$, for all the considered samples.

The mean stained cross sectional area, calculated by considering the samples from the two fields, is illustrated in Fig. 8, as a function of soil depth. ANOVA showed that the mean stained area for the samples collected in field 1 was

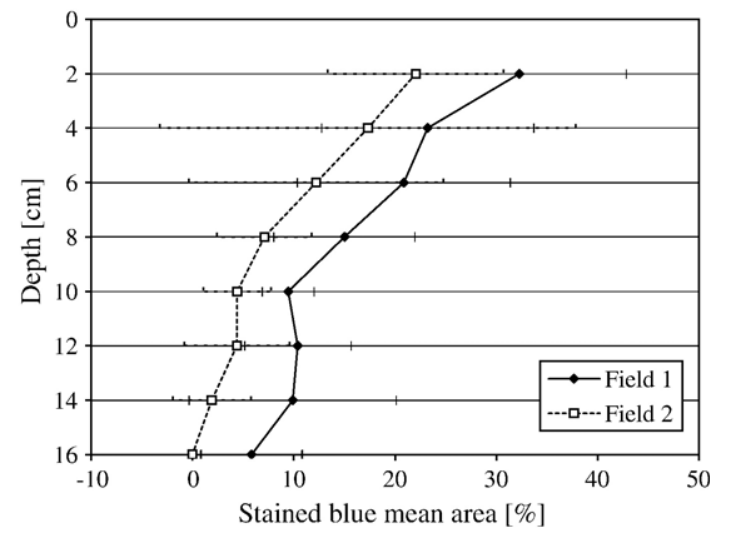

Fig. 8. Stained blue mean cross sectional area obtained for samples of fields 1 and 2 as a function of soil depth. 
significantly higher than that obtained on samples of field 2 . However, the $\mathrm{L}$ sample showed a negligible blue stained area at the depth $D^{\prime}{ }_{\text {max }}=16 \mathrm{~cm}$ (Fig. 7c), while for the other samples collected in the same field no methylene blue patterns were found at the same depth. This result was in agreement with the flow behaviour observed in this core, which indicated a certain occurrence of bypass flow. Instead, methylene blue patterns were found on the cores from field 1 at $D^{\prime}{ }_{\text {max }}=16 \mathrm{~cm}$ (Fig. 7c). This difference in terms of macropores' continuity between fields 1 and 2 is an agreement and explains the different hydraulic behaviour between the cores from the two fields, as bypass flow has been recognized to depend on macropores' continuity (Bouma, 1991). The higher raindrop impact and the non-point water application involved in the sprinkler irrigation system are likely to have determined, over the years, changes in soil structure compared to the pre-existing structural conditions still existing in the drip irrigated field. Slaking of soil aggregates (Agassi et al., 1981), dispersion of clay particles and transport of these particles by water with accumulation into a region of a reduced porosity, where they became clogged and plugged the conducting pores (Ben-Hur et al., 1998), may have been the mechanisms affecting the pre-existing soil structural condition. These mechanisms have been previously recognized to alter soil structural and hydraulic characteristics (Shainberg et al., 1981; Crescimanno et al., 1995).

Previous investigations showed that bypass flow is a mechanism inducing salt-leaching (Crescimanno et al., 2002), Moreover, Tanton et al. (1988), evidenced the role of water flow through natural macropores, showing that reclamation of saline clay soils can be possible only when freely draining macropores, effective in conducting water and for leaching, are present into the soil. As a consequence, management practices affecting soil structure, and altering macropores' continuity, should be avoided in clay soils.

\section{Summary and conclusions}

This investigation explored differences in morphological, physical and hydraulic behaviour of a Sicilian Vertisol under two irrigation systems, i.e. drip and sprinkler.

Field application of methylene blue showed the presence of continuous macropores penetrating up to a depth of $20-25 \mathrm{~cm}$ from the soil surface in the field (field 1) where the drip system was in use. This was considered to be the original structure of this soil. Instead, macropores terminating at a depth ranging between 5 and $10 \mathrm{~cm}$ from the soil surface were observed in the sprinkler irrigated field (field 2). A different hydraulic behaviour was found by laboratory measurement of bypass flow on soil cores taken from the two fields. Specifically, higher values of the saturated hydraulic conductivity were found in the cores from the drip irrigated field compared to those sampled in the sprinkler field. In addition, no bypass flow was measured in the columns under the sprinkler field. On the other hand, high rates and amounts of bypass flow were measured in the cores taken from the drip irrigated field.

Being the conditions in the two fields comparable in terms of topography and quality of water used for irrigation, physical properties, shrinkage and potential cracking, as well as of crop and tillage, the different hydraulic behaviour observed in the cores taken from the two fields could be explained by the difference in terms of macropores' continuity between fields 1 and 2 .

The higher raindrop impact characterizing the sprinkler system could have determined slaking of soil aggregates, dispersion of clay particles and detachment of these particles from the surface and their movement into the pores, causing a partial occlusion of the macropores and determining a different hydraulic and (bypass)-flow behaviour. Being bypass flow a mechanism inducing leaching of solutes, these results indicated that management practices affecting macropores' continuity should be avoided in clay soils. Further investigation is under way to explore the influence of the different flow behaviour observed in the two fields on accumulation and leaching of solutes.

\section{Acknowledgement}

This research was supported by the "Environment and Climate Programme" under contract ENV4-CT97-0681.

\section{References}

Agassi, M., Shainberg, I., Morin, J., 1981. Effect of electrolyte concentration and soil sodicity on the infiltration rate and crust formation. Soil Sci. Soc. Am. J. 45, 848-851.

Ben-Hur, M., 1994. Runoff erosion and polymer application in moving sprinkler irrigation. Soil Sci. 158, 283-290.

Ben-Hur, M., Assouline, S., 2002. Tillage effects on water and salt distribution in a Vertisol during effluent irrigation and rainfall. Agron. J. 94, 1295-1304.

Ben-Hur, M., Plaut, Z., Shainberg, I., Meiri, A., Agassi, M., 1989. Cotton canopy and drying effects on runoff during irrigation with moving sprinkler systems. Agron. J. 81, 751-757.

Ben-Hur, M., Plaut, Z., Levy, G.J., Agassi, M., Shainberg, I., 1995. Surface runoff, uniformity of water distribution and yield of peanut irrigation with a moving sprinkler systems. Agron. J. 87, 609-613.

Ben-Hur, M., Agassi, M., Keren, R., Zhang, J., 1998. Compaction, aging and raindrop impact effect on hydraulic properties of saline and sodic Vertisols. Soil Sci. Soc. Am. J. 62, 1377-1383.

Beven, K., Germann, P., 1982. Macropore and water flows in soils. Water Resour. Res. 18, 1311-1325

Booltink, H.W.G., Bouma, J., 1991. Physical and morphological characterization of bypass flow in a well-structured clay soil. Soil Sci. Soc. Am. J. 55, 1249-1254.

Booltink, H.W.G., Bouma, J., Gimenez, D., 1991. A suction crust infiltrometer for measuring hydraulic conductivity of unsaturated soil near saturation. Soil Sci. Soc. Am. J. 55, 566-568.

Booltink, H.W.G., Hatano, R., Bouma, J., 1993. Measurement and simulation of bypass flow in a structured clay soil: a physico-morphological approach. J. Hydrol. 148, 149-168.

Bouma, J., 1984. Using soil morphology to develop measurement methods and simulation techniques for water movement in heavy clay soils. In: Bouma, J., Raats, P.A.C. (Eds.), Water and Solute Movement in Heavy Clay Soils. Int. Soc. Soil Science (ISSS) Symp. Inst. Land Reclamation and Irrigation (ILRI), Wageningen, The Netherland, vol. 37, pp. 298-316.

Bouma, J., 1991. Influence of soil macroporosity on environmental quality. Adv. Agron. 46, 1-37.

Bouma, J., Dekker, L.W., 1978. A case study on infiltration into dry clay soil. I. Morphological observations. Geoderma 20, 27-40.

Crescimanno, G., Provenzano, G., 1999. Soil shrinkage characteristic curve in clay soils: measurement and prediction. Soil Sci. Soc. Am. J. 63, 25-32. 
Crescimanno, G., Iovino, M., Provenzano, G., 1995. Influence of salinity and sodicity on soil structural and hydraulic characteristic. Soil Sci. Soc. Am. J. 59, 1701-1708.

Crescimanno, G., Provenzano, G., Booltink, H.W.G., 2002. The effect of alternating different water qualities on accumulation and leaching of solutes in Mediterranean cracking soils. Hydrol. Proc. 16, 717-730.

Droogers, P., Stein, A., Bouma, J., de Boer, G., 1998. Parameters for describing soil macroporosity derived from staining patterns. Geoderma 83, 293-308.

FAO, Food and Agriculture Organization of the United Nations, 1990. Soil Map of the World. Revised Legend with Corrections. FAO, Rome.

Gilley, J.R., Mielke, L.N., 1980. Conserving energy with low pressure center pivot. J. Irrig. Drain. Div. Am. Soc. Civ. Eng. 106, 49-59.

Grossman, R.B., Brasher, B.R., Franzmeier, D.P., Walker, J.L., 1968. Linear extensibility as calculated from natural clod bulk density measurements. Soil Sci. Soc. Am. Proc. 32, 570-573.

Heijs, A.W.J., Ritsema, C.J., Dekker, L.W., 1996. Three dimensional visualization of preferential flow patterns in two soils. Geoderma 70, 101-116.

Huang, Z.B., Assouline, S., Zilberman, J., Ben-Hur, M., 2000. Tillage and saline irrigation effects on water and salt distribution in a sloping field. Soil Sci. Soc. Am. J. 64, 2096-2102.

Kay, B., 1990. Rates of change of soil structure under different cropping systems. Adv. Soil Sci. 12, 1-52.

Kemper, W.D., Koch, E.J., 1966. Aggregate stability of soils from Western United States of America and Canada. Colorado Agric. Exp. Stn. Bull., vol. 1355. USDA-ARS and Colorado Agric. Exp. Stn, Fort Collins, CO.

Kung, K.J.S., Kladivko, E.J., Gisn, T.J., Stenhuis, T.S., Bubenzer, G., Helling, C.S., 2000. Quantifying preferential flow by breakthrough of sequentially applied tracers: silt loam soil. Sci. Soc. Am. J. 64, 1296-1304.

Nielsen, D.R., Van Genuchten, M.T., Biggar, J.W., 1986. Water flow and solute transport processes in the unsaturated zone. Water Resour. Res. 22, 89-108.
Parker, J.C., Amos, D.F., Kaster, D.L., 1977. An evaluation of several methods of estimating soil volume change. Soil Sci. Soc. Am. J. 41, 1059-1064.

Rands, J.G., Hodgkinson, R.A., Thornburn, A.A., Chase, R.A., 1986. The breakdown of field drainage systems due to deflocculation in the coastal marshes of England. In: Smith, K.V.H, Rycroft, D.W. (Eds.), The Extend of the Problem and Possible Remedies. . Hydraulic Design in Water Res. Eng. Land Drain. Proc. 2nd Int. Conf. Southampton University, U.K. Springer, Berlin, pp. 433-442.

Shainberg, I., Rhoades, J.D., Prather, R.J., 1981. Effect of low electrolyte concentration on clay dispersion and hydraulic conductivity of a sodic soil. Soil Sci. Soc. Am. J. 45, 273-277.

Soil Survey Staff, 1992. Keys to soil taxonomy, 8th ed. SMSS Technical Monograph, vol. 19. Pocahontas Press, Blacksbourg, VA. 556 pp.

Steenhuis, T.S., Parlange, J.Y., 1991. Preferential flow in structured and sandy soils. In: Gish, T.I., Ahirmonhammadi, A. (Eds.), Preferential Flow. Am. Soc. Agric. Eng., St. Joseph, Mi., pp. 12-21.

Tanton, T.W., Rycroft, D.W., Wilkinson, F.M., 1988. The leaching of salts from saline heavy clay soils: factors affecting the leaching processes. Soil Use and Manage. 4, 133-139.

Van Stiphout, T.P.J., van Lanen, H.A.J., Boersma, O.H., Bouma, J., 1987. The effect of bypass flow and internal catchment of rain on the water regime in a clay loam grassland. J. Hydrol. 95, 1-11.

Warrick, A.W., Gardner, W.R., 1983. Crop yield as affected by spatial variations of soil and irrigation. Water Resour. Res. 19, 181-186.

Williams, J., Chartres, C.J., 1991. Sustaining productive pastures in the tropics. 1. Managing the soil resource. Trop. Grassl. 25, 3-84.

Yaalon, D.H., Kalmar, D., 1978. Dynamics of cracking and swelling of clay soils: displacement of skeletal grains, optimum depth of slickensides, and rate of intra-pedonic turbation. Earth Surf. Proc. 3, 31-42. 